\title{
The distribution and requirements of microtubules and microfilaments during fertilization and parthenogenesis in pig oocytes
}

\author{
N-H. Kim ${ }^{1,2}$, K-S. Chung ${ }^{2}$ and B. N. Day ${ }^{1 *}$ \\ ${ }^{1}$ Animal Sciences Research Center, University of Missouri-Columbia, Columbia, MO 65211, USA; and \\ ${ }^{2}$ Animal Resources Research Center, Academy of Life Science, Kon Kuk University, Seoul 143-701, Korea
}

\begin{abstract}
Microtubules and microfilaments are major cytoskeletal elements in mammalian ova and are important modulators of many fertilization and post-fertilization events. In this study, the integrated distribution of microtubules and microfilaments in pig oocytes were examined under a laser scanning confocal microscope, and the requirements of their assembly during in vitro fertilization and parthenogenesis in in vitro matured pig oocytes were determined. After sperm penetration, an aster of microtubules was produced in the spermatozoon, and this microtubule aster filled the whole cytoplasm during pronuclear movement. During pronuclear formation after activation by insemination, microfilaments became concentrated at the male and female pronuclei and, after electrical stimulation, at the female pronucleus. At metaphase of cleavage, microtubules were detected in the spindle and microfilaments were found mainly in the cortex. At anaphase, microtubule asters assembled at each spindle pole. During cleavage, large asters filled each daughter blastomere and a microfilament-rich cleavage furrow was observed. Cytochalasin B, a microfilament inhibitor, inhibited microfilament polymerization but affected neither pronuclear formation nor movement. However, syngamy and cell division were inhibited in eggs treated with cytochalasin B. Treatment with nocodazole after sperm penetration inhibited microtubule assembly and prevented migration leading to pronuclear union and cell division. These results indicate that microtubule and microfilament assembly in pig oocytes are integrated during fertilization and are required for the union of sperm and egg nuclei and for subsequent cell division.
\end{abstract}

\section{Introduction}

At fertilization, male and female nuclei undergo extensive rearrangements which are necessary for the union of the paternal and maternal genomes. Changes in nuclear structure include male and female pronuclear formation, pronuclear movements, intermixing of paternal and maternal genomes and mitotic processes for the completion of the fertilization processes. In a previous study that used the microtubule inhibitors, colcemid and nocodazole (Schatten et al., 1989), it was shown that microtubule assembly is required for the formation of male and female pronuclei as well as for pronuclear migration in mice. However, microtubules may not be the only cytoskeletal element for pronuclear migration. In experiments using the microfilament inhibitor latrunculin (Schatten et al., 1986), it has been shown that microfilaments also play a role in pronuclear movement. In the mouse oocyte, microfilaments became concentrated around both pronuclei after fertilization (Maro et al., 1984).

Although the changes of chromatin are related to microtubule and microfilament dynamics during fertilization (Maro et al., 1985; Van Blerkom and Bell, 1986; Webb et al., 1986; Kim

*Correspondence.

Revised manuscript received 12 February 1997. et al., 1996a, b), the exact mechanism whereby chromosomes (either male or female) organize cytoskeletons is poorly understood. Furthermore, except in the mouse oocyte, little information is available on the role of microtubules and microfilaments and their interaction during fertilization and parthenogenesis in mammalian ova. Recently, we have reported microtubule assembly during pig fertilization and parthenogenesis, and demonstrated that a functional centrosome is the result of blending of paternal and maternal centrosomal components, and that microtubules are involved in pronuclear migration (Kim et al., 1996b). In the present study, the integrated distribution and role of microtubules and microfilaments in pronuclear migration and two-cell division during fertilization and parthenogenesis in pigs are investigated.

\section{Materials and Methods}

In vitro maturation

Pig oocyte-cumulus complexes with uniform ooplasm and a compact cumulus cell mass were prepared in Hepes-buffered TALP medium containing $0.1 \%$ polyvinylalcohol (Hepes-TLPVA) as described by Funahashi et al. (1994). Culture medium 


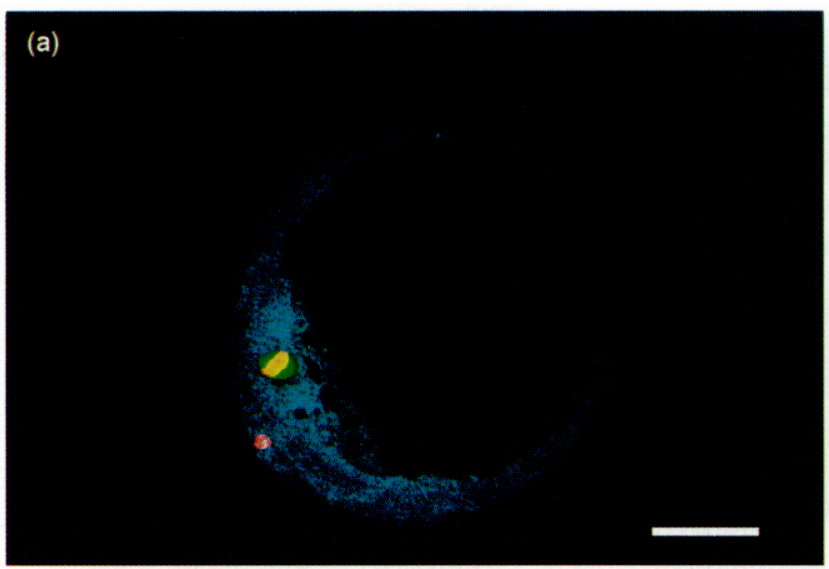

(b)
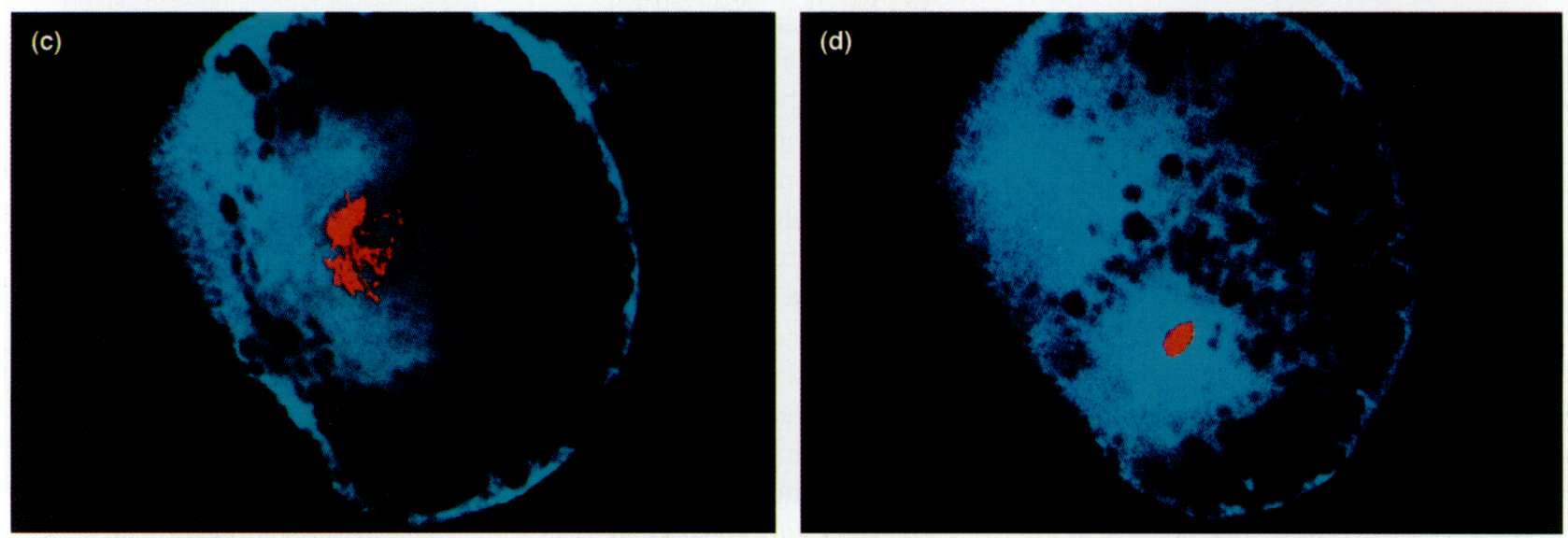

(e)

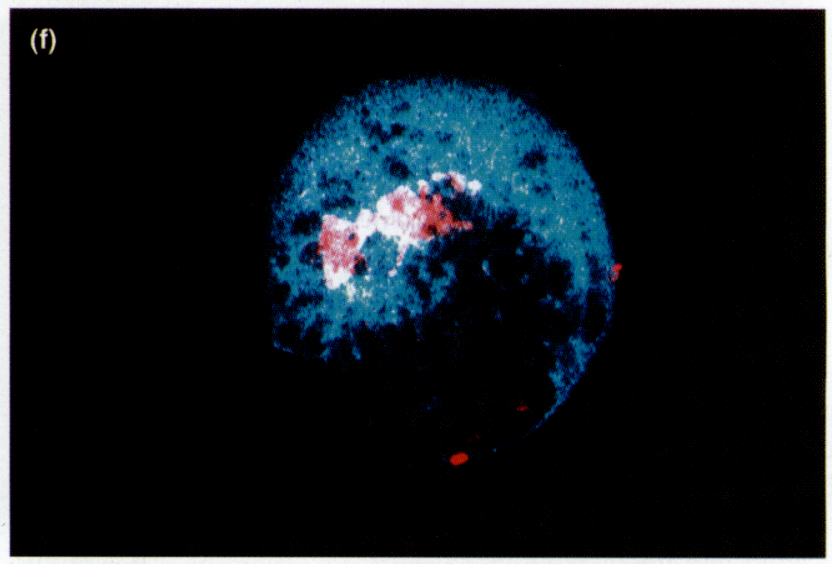

(g)

(h) 
for in vitro maturation was BSA-free NCSU23 medium (NCSU23, Petters and Wells, 1993) supplemented with $10 \%$ $(\mathrm{v} / \mathrm{v})$ pig follicular fluid $(\mathrm{pFF}), 10 \mathrm{i} . \mathrm{u} . \mathrm{eCG} \mathrm{\textrm {ml } ^ { - 1 }}$ (Intervet America Inc., Millsboro, DE) and 10 i.u. hCG ml ${ }^{-1}$ (Lympo Med Inc., Rosemont, IL). Fifty oocyte-cumulus complexes were transferred to $500 \mu \mathrm{l}$ of NCSU23, covered with paraffin oil (light mineral oil, number 0121-4; Fisher Scientific, Fair Lawn, $\mathrm{NJ}$ ) in a four-well culture plate and then cultured for $22 \mathrm{~h}$ at $39^{\circ} \mathrm{C}$ in an atmosphere of $5 \% \mathrm{CO}_{2}$ in air. The oocyte-cumulus complexes were then transferred to $500 \mu \mathrm{l}$ of NCSU23 without hormonal supplements and cultured for an additional $22 \mathrm{~h}$ at $39^{\circ} \mathrm{C}$ in $5 \% \mathrm{CO}_{2}$ in air (Funahashi and Day, 1993).

\section{In vitro fertilization}

Sperm-rich fractions $(15 \mathrm{ml})$ were collected from boars by the gloved hand method and, after adding antibioticantimycotic solution (GIBCO BRL, Life Technology Inc., Grand Island, NY), the semen sample was kept at $20^{\circ} \mathrm{C}$ for $16 \mathrm{~h}$. The semen was washed three times with $0.9 \%(\mathrm{w} / \mathrm{v}) \mathrm{NaCl}$ supplemented with $1 \mathrm{mg} \mathrm{BSA} \mathrm{ml}^{-1}$ (Fraction V, Sigma Chemical Co., St Louis, MO) by centrifugation at $600 \mathrm{~g}$ for $3 \mathrm{~min}$. At the end of washing, the pellets containing spermatozoa were resuspended at $2 \times 10^{8}$ cells in modified TCM-199 $\mathrm{ml}^{-1}$ (Funahashi et al., 1994; Sigma) at $\mathrm{pH} 7.8$ supplemented with $1 \% \mathrm{pFF}$. The sperm suspension was incubated for $90 \mathrm{~min}$ at $39^{\circ} \mathrm{C}$ in an atmosphere of $5 \% \mathrm{CO}_{2}$ in air. Ten oocytes were washed three times with modified TCM-199 supplemented with $10 \mathrm{mmol}$ caffeine sodium benzoate $\mathrm{l}^{-1}$ and $4 \mathrm{mg} \mathrm{BSA} \mathrm{ml}^{-1}$ at pH 7.4 and placed into a $50 \mu \mathrm{l}$ droplet of the same medium under paraffin oil. Fifty microlitres of diluted preincubated spermatozoa was added to $50 \mu \mathrm{l}$ of the medium containing oocytes so that a final sperm concentration of $1 \times 10^{6}$ cells $\mathrm{ml}^{-1}$ was obtained. Oocytes were co-cultured with spermatozoa for $6 \mathrm{~h}$ at $39^{\circ} \mathrm{C}$ in an atmosphere of $5 \% \mathrm{CO}_{2}$ in air. The oocytes were then transferred to $500 \mu \mathrm{l}$ of fresh NCSU23 and cultured at $39^{\circ} \mathrm{C}$ in an atmosphere of $5 \% \mathrm{CO}_{2}$ in air. The oocytes were fixed at 6, 9, 12, 24 and $36 \mathrm{~h}$ after insemination.

\section{Oocyte activation}

Before electrical stimulation, oocytes matured in vitro were denuded of cumulus cells, washed and preincubated for $5 \mathrm{~min}$ in electroporation medium $10.25 \mathrm{~mol}$ mannitol $1^{-1}$ supplemented with $0.01 \%$ polyvinyl alcohol, $0.5 \mathrm{mmol}$ Hepes $\mathrm{l}^{-1}$, and $100 \mathrm{mmol} \mathrm{CaCl} 2 \cdot 2 \mathrm{H}_{2} \mathrm{Ol}^{-1}$ and $25 \mathrm{mmol} \mathrm{MgCl}_{2} \cdot 6 \mathrm{H}_{2} \mathrm{O}$ $\mathrm{l}^{-1} ; \mathrm{pH}$ 7.2). Electrical stimulation to induce activation was delivered via a BTX electrocell manipulator (Biotechnologies and Experimental Research, Inc., San Diego, CA) to a chamber with two parallel platinum wire electrodes $(200 \mathrm{~mm}$ outer diameter) spaced $1 \mathrm{~mm}$ apart and overlaid with electroporation medium as described above. A single DC pulse of $1.2 \mathrm{kV} \mathrm{cm}^{-1}$ for $30 \mu \mathrm{s}$ was used for electrical stimulation. After a $2 \mathrm{~min}$ recovery, the oocytes were transferred to $500 \mu \mathrm{l}$ of Whitten's medium and cultured at $39^{\circ} \mathrm{C}$ in an atmosphere of $5 \% \mathrm{CO}_{2}$ in air. The oocytes were fixed at 1.5, 3, 6, 12, 18 and $24 \mathrm{~h}$ after electrical stimulation for immunocytochemistry.

\section{Immunofluorescence microscopy}

At specific time points, the oocytes were permeabilized in a modified Buffer M (Simerly and Schatten, 1993; 25\% glycerol, $50 \mathrm{mmol} \mathrm{KCl}{ }^{-1}, 0.5 \mathrm{mmol} \mathrm{MgCl}_{2} \mathrm{l}^{-1}$, $0.1 \mathrm{mmol}$ ethylendiaminetetraacetic acid $\mathrm{l}^{-1}, 1 \mathrm{~mol} \beta$-mercaptoethanol $\mathrm{l}^{-\mathrm{I}}$,

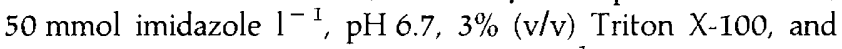
$25 \mu \mathrm{mol}$ phenylmethylsulfonyl fluoride $\mathrm{I}^{-1}$ ) for $20 \mathrm{~min}$, fixed in methanol at $20^{\circ} \mathrm{C}$ for $10 \mathrm{~min}$ and stored in PBS containing $0.02 \%(\mathrm{w} / \mathrm{v})$ sodium azide and $0.1 \%(\mathrm{w} / \mathrm{v})$ BSA for $2-7$ days at $4^{\circ} \mathrm{C}$.

Microtubule localization was performed using $\alpha$-tubulin monoclonal antibody (Sigma). Fixed oocytes were incubated for $90 \mathrm{~min}$ at $39^{\circ} \mathrm{C}$ with antibody diluted 1:300 in PBS. After several washes with PBS containing $0.5 \%$ Triton $X-100$ and $0.5 \%$ BSA, oocytes were incubated in a block solution $10.1 \mathrm{~mol}$ glycine, $1 \%$ goat serum, $0.01 \%$ Triton X-100, $1 \%$ powdered milk, $0.5 \%$ BSA and $0.02 \%$ sodium azide $\mathrm{l}^{-1}$ ) at $39^{\circ} \mathrm{C}$ for $1 \mathrm{~h}$. The blocking was followed by incubation in Rhodaminelabelled goat anti-mouse antibody (Sigma). DNA was observed by exposure to $5 \mu \mathrm{g}$ TOTO-3 $\mathrm{ml}^{-1}$ (Molecular probe, Eugene, OR). Stained oocytes were then mounted under a coverslip with antifade mounting medium (Vectashild, Vector Lab. Burlingame, CA) to retard photobleaching.

Slides were examined by a laser-scanning confocal microscope using a BIO-RAD MRC 600 equipped with a Krypto-argon ion laser. Images were recorded digitally and archived on an erasable magnetic optical diskette.

\section{Drug treatments}

The effects of nocodazole (a microtubule inhibitor), cytochalasin B (a microfilament inhibitor), and taxol (a microtubule stabilizer on pronuclear formation and movement) were examined during in vitro fertilization. Stock solutions of $1 \mathrm{mmol}$ nocodazole $\mathrm{l}^{-1}$ (Sigma), $5 \mathrm{mmol}$ of cytochalasin B $\mathrm{I}^{-1}$ (Sigma) and 1 mmol taxol $I^{-1}$ (Sigma) in dimethyl sulfoxide were used. The stock solution was stored at $-20^{\circ} \mathrm{C}$ and diluted to $10 \mu \mathrm{mol}$ nocodazole $\mathrm{l}^{-1}$ and $5 \mu \mathrm{mol}$ cytochalasin $\mathrm{B}^{-1}$ in

Fig. 1. Laser scanning confocal microscopic images of microtubules, microfilaments and chromatin in the pig oocyte after fertilization. Green, microtubules; blue, microfilaments; red, chromatin. (a) Microtubules were observed in the meiotic spindle in the oocyte at metaphase II. Two microfilament domains: a microfilament-rich domain and a microfilament-thin domain, were observed. (b) After sperm penetration, microtubules were found in association with the incorporated sperm head. (c, d) The same oocyte observed at different focal points. (c) When focused on the female nucleus (about $50 \mathrm{~mm}$ from the surface), microfilaments were concentrated to the female structure. (d) Microfilaments were also observed within the male chromatin (d). (e) At the time of pronuclear centralization, microtubules filled the cytoplasm. (f) Microfilaments were concentrated in both the male and female nuclear structure during pronuclear movements. (g) An astral bipolar spindle was observed at metaphase and microfilaments were also observed in the cortex. (h) At the time of division to the two-cell stage, thick microfilament furrows were observed between blastomeres. Scale bar represents $25 \mathrm{~mm}$. 

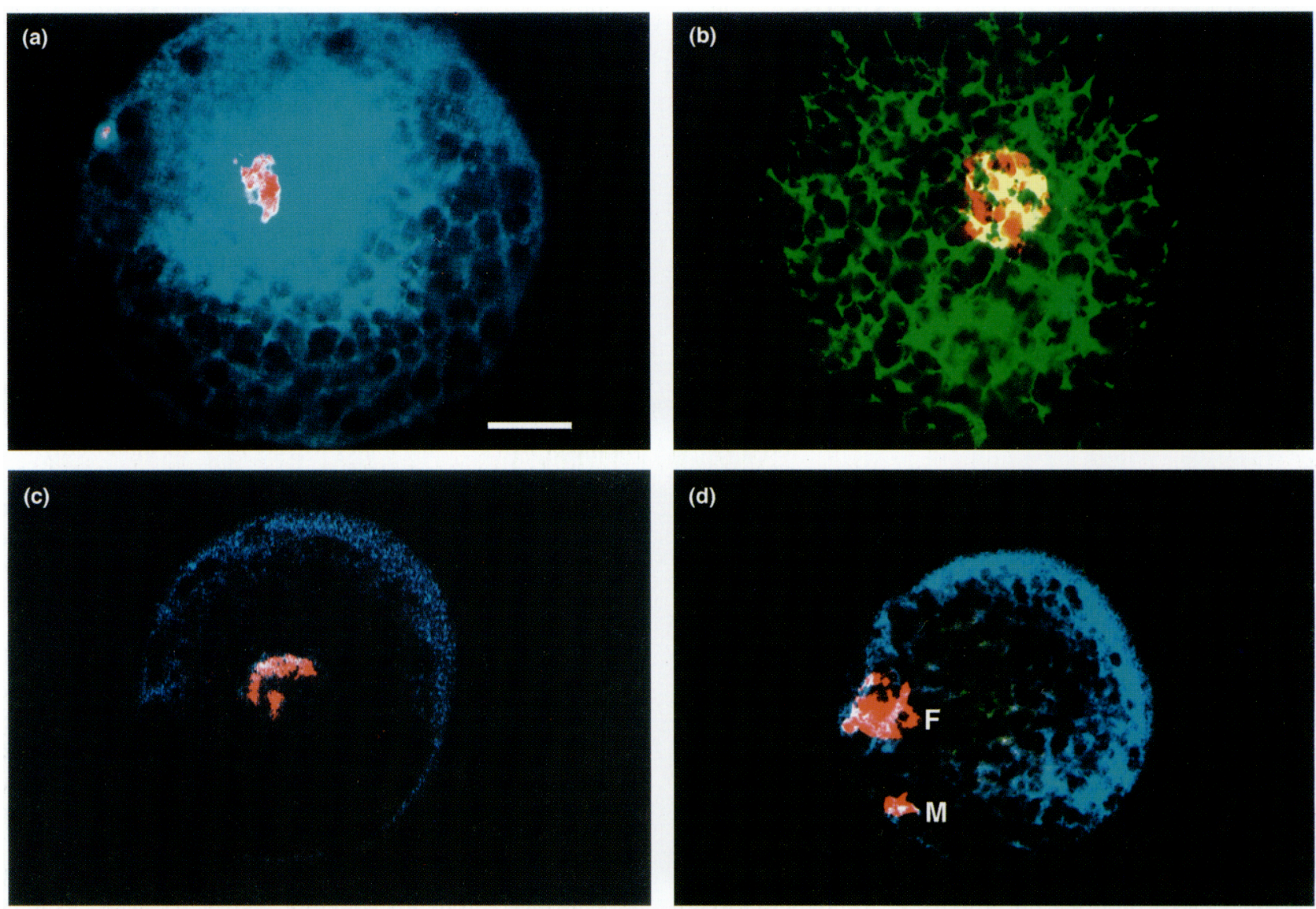

(d)
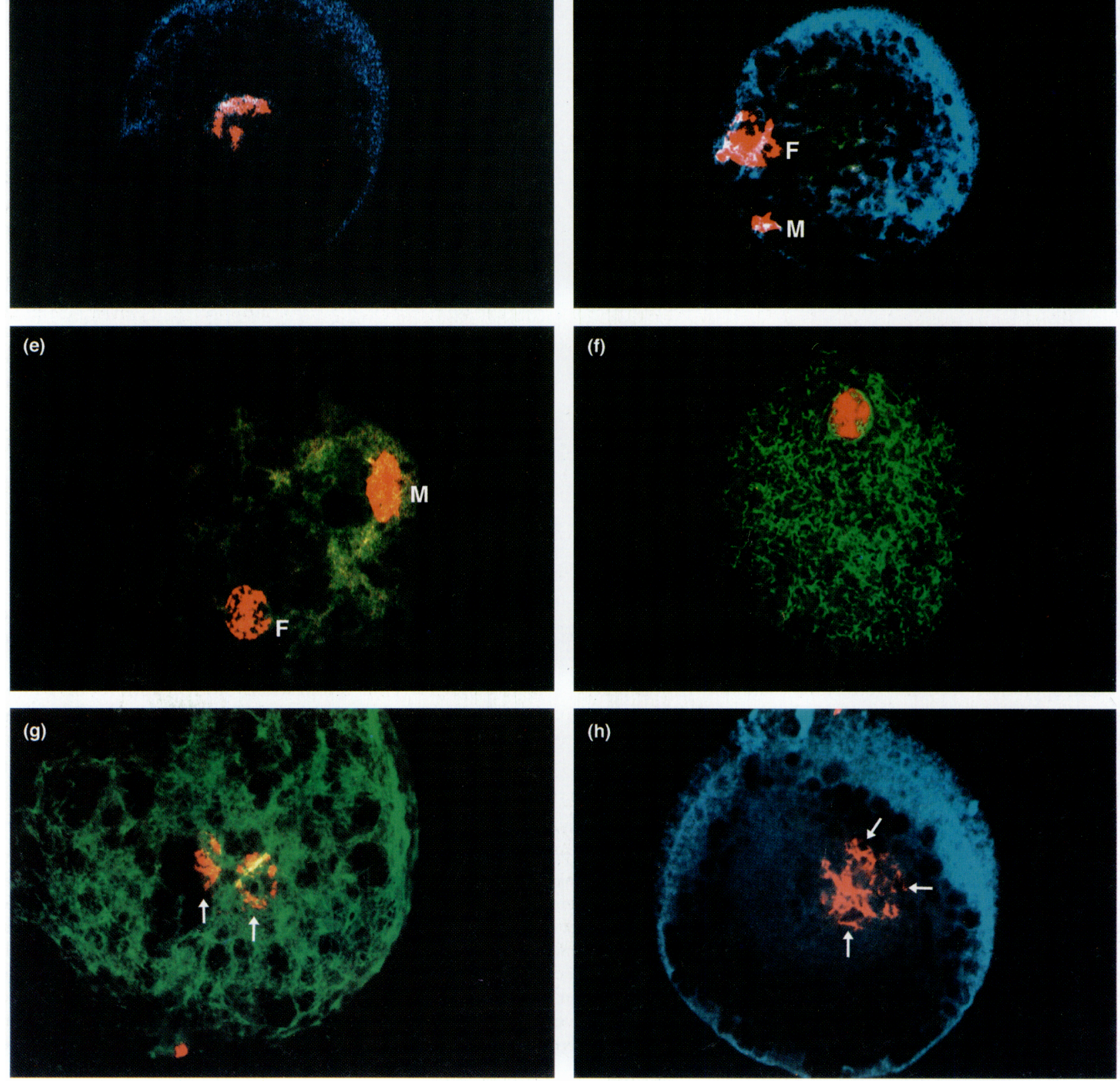
NCSU23 before treatment of oocytes. Oocytes were treated with drugs between $6 \mathrm{~h}$ and $12 \mathrm{~h}$, and between 12 and $24 \mathrm{~h}$ after insemination. At least three replicates were conducted for each experiment.

\section{Statistical analysis}

Statistical differences were determined by Fisher's protected least significant difference test.

\section{Results}

\section{Microtubule and microfilament dynamics during fertilization and parthenogenesis}

In oocytes at the metaphase II stage, microtubules were detected in the second meiotic spindle, and two microfilament domains (a microfilament-rich and a microfilament-thin domain) were present in the egg (Fig. 1a). In almost all of the unfertilized mature oocytes (76 of $89,85 \%$ ), the metaphase chromatin with spindle was located in the thick microfilament domain (Fig. 1a). Male pronuclear formation was observed between $9 \mathrm{~h}(24$ of $107,22 \%)$ and $12 \mathrm{~h}(69$ of $104,66 \%)$ after insemination. At $9 \mathrm{~h}$ after sperm insemination, the sperm asters (55 of $97,57 \%$ ) were observed adjacent to the incorporated sperm head (Fig. 1b). Polyspermic penetration was found in 46 (47\%) zygotes at $9 \mathrm{~h}$. As observed by Kim et al., (1996b) in polyspermic zygotes, multiple sperm asters were found in association with each penetrated spermatozoon. During pronuclear formation, microfilaments became concentrated to both the male and female chromatin (Fig. Ic, d). At pronuclear apposition ( 21 of $69,30 \%$ at $24 \mathrm{~h}$ after insemination), microtubules organized by sperm components filled the cytoplasm and microfilaments became concentrated to both the male and female pronuclei (Fig. 1e, f). At mitotic metaphase (3 of 69, 4\% at $24 \mathrm{~h}$ after insemination), microtubules were detected in the spindle and microfilaments were found mainly in the cortex (Fig. 1g). During cleavage (4 of 69, 6\%), large asters filled each daughter blastomere (data not shown) and a microfilament-rich cleavage furrow was observed (Fig. Th). After electrical stimulation, a pronucleus was observed between $3 \mathrm{~h}$ ( 15 of $46,33 \%$ ) and $6 \mathrm{~h}$ (29 of $43,67 \%)$. During pronuclear formation after electrical stimulation, microfilaments concentrated to the female pronuclear structure and a dense network of microtubules was found throughout the cytoplasm (Fig. 2a, b). Under the same culture conditions, the pig oocytes were cultured to establish
Table 1. Development in vitro of pig oocytes after insemination and electrical stimulation

\begin{tabular}{|c|c|c|c|}
\hline \multirow[b]{2}{*}{ Treatment } & \multirow{2}{*}{$\begin{array}{l}\text { Number } \\
\text { of oocytes } \\
\text { examined }\end{array}$} & \multicolumn{2}{|c|}{ Number of oocytes developed (\%) } \\
\hline & & $\begin{array}{l}\text { Two-cell } \\
\text { cleavage }\end{array}$ & $\begin{array}{c}\text { Morulae/ } \\
\text { blastocysts }\end{array}$ \\
\hline Insemination & 130 & $79(61)$ & $38(29)$ \\
\hline Electrical stimulation & 129 & $71(55)$ & $31(24)$ \\
\hline
\end{tabular}

cleavage and developmental ability. The rates of normal cleavage and the developmental ability of pig oocytes to the morula and blastocyst stages after in vitro fertilization or electrical stimulation are summarized (Table 1).

\section{Effects of cytoskeletal inhibitors during pronuclear formation and apposition}

Treatment with cytochalasin B after electrical stimulation or insemination inhibited microfilament polymerization, but did not affect pronuclear formation or movement (Fig. 2c). However, gamete union and cell division were not observed in the cytochalasin B treated eggs (Table 2). Treatment with nocodazole after sperm penetration inhibited microtubule assembly and prevented migration leading to centralized pronuclei and cell division (Fig. 2d, Table 2). Neither the microtubule nor the microfilament inhibitor inhibited pronuclear formation (Fig. 2e). Taxol, which stabilizes microtubules (Maro et al., 1986; Schatten et al., 1989), did not prevent pronuclear formation but did prevent pronuclear movement. After nocodazole treatment, taxol induced microtubules in the cytoplasm (Fig. 2f). After $3 \mathrm{~h}$ recovery from nocodazole, treatment with taxol induced formation of microtubules in the cytoplasm (Fig. 2g). Treatment with cytochalasin B induced multiple pronuclei in the cytoplasm, and a $3 \mathrm{~h}$ recovery period allowed the formation of microfilaments in the cytoplasm (Fig. 2h).

\section{Discussion}

This study examined the integral distribution of microtubules and microfilaments and demonstrated a need for their assembly for pronuclear formation and migration, as well as cleavage after fertilization and parthenogenesis, in the pig oocyte. The

Fig. 2. Laser scanning confocal microscopic images of microtubules, microfilaments and chromatin in pig oocytes after parthenogenetic activation and fertilization. Green, microtubules; blue, microfilaments; red, chromatin. M, male chromatin; F, female chromatin (a) During pronuclear formation after parthenogenetic activation, microfilaments were concentrated in the pronucleus. (b) A dense network of microtubules was observed in the parthenote during pronuclear movements. (c) Treatment with cytochalasin B after parthenogenetic activation inhibited microfilament polymerization, but did not inhibit female pronuclear formation. (d) During fertilization, nocodazole did not inhibit male and female pronuclear formation, but did prevent centralization of pronuclei during fertilization. (e) During fertilization, treatment with either nocodazole or cytochalasin B did not inhibit pronuclear formation, but did inhibit syngamy. ( $\mathrm{f}$ ) Treatment with taxol induced microtubule foci in the cytoplasm during pronuclear formation after parthenogenetic activation. (g) After recovery from the microtubule inhibition, taxol induced microtubules were seen in the cytoplasm. After parthenogenetic activation, two pronuclei were observed in the cytoplasm (arrows). (h) Recovery from treatment with cytochalasin B allowed microfilament formation in the cytoplasm. Three pronuclei were observed in the cytoplasm during parthenogenesis (arrows). Scale bar represents $25 \mathrm{~mm}$. 
Table 2. Treatment in vitro of pig oocytes with nocodazole and cytochalasin $B$ between $12 \mathrm{~h}$ and $24 \mathrm{~h}$ after insemination

\begin{tabular}{|c|c|c|c|c|c|}
\hline \multirow[b]{2}{*}{ Treatment } & \multirow{2}{*}{$\begin{array}{l}\text { Number } \\
\text { of oocytes } \\
\text { examined }\end{array}$} & \multicolumn{4}{|c|}{ Number of oocytes (\%) with } \\
\hline & & $\begin{array}{c}\text { Female pronucleus } \\
\text { migration }\end{array}$ & $\begin{array}{l}\text { Male pronucleus } \\
\text { migration }\end{array}$ & Syngamy & $\begin{array}{c}\text { Mitosis } \\
\text { (cell division) }\end{array}$ \\
\hline Control & 56 & $42(75)$ & $32(57)$ & $16(29)$ & $4(7)$ \\
\hline Nocodazole & 48 & $15(31)^{*}$ & $2(4)$ & - & - \\
\hline
\end{tabular}

$* P<0.05$ compared with controls.

sperm aster enlarged during sperm decondensation and extended throughout the cytoplasm at the time of pronuclear apposition. Treatment with nocodazole inhibited pronuclear migration, suggesting a role for microtubules during pronuclear apposition in the pig. In most animals, the microtubules of the sperm aster are responsible for moving the male and female pronuclei from the inner face of the oocyte cortex in the egg cytoplasm (Albertson, 1984; Schatten et al., 1986; Le Guen and Crozet, 1989; Yllera-Fernandez et al., 1992; Long et al., 1993; Breed et al., 1994). However, in mice, numerous cytoplasmic microtubule foci have been observed in the cytoplasm (Maro ef al., 1985; Schatten et al., 1985). During pronuclear development, the asters containing microtubules increased in size as the cytoplasm became filled with a microtubule matrix. Although the pattern of microtubule configuration during mouse fertilization is atypical, microtubule activity is required to achieve pronuclear union (Schatten et al., 1986). Pronuclei are embedded within the microtubule matrix and, by a process involving both assembly and disassembly, the male and female pronuclei are moved into apposition at the centre of the cell. Rieder and Salmon (1994) proposed that the female nucleus is covered with dynein-like, minus-end directed motors that translocate the female pronucleus from the periphery of the sperm aster towards its centre. While the sperm aster enlarges, it is likely that it moves the decondensing male pronucleus to the centre of the oocyte. The force responsible for male pronuclear movement may be the aster ejection force, which consists of kinesin-like, plus-end directed motors (Schatten, 1994).

The distribution of microfilaments has been studied in mammalian ova. In mature mouse (Maro et al., 1984) and rat (Zernicka-Goetz et al., 1993) oocytes, microfilaments are located mainly in the cell cortex overlying the meiotic spindle. This domain, rich in microfilaments, appears to be responsible for maintenance of the meiotic spindle and chromosomes in a peripheral position (Webb et al., 1986). Maro et al. (1984) found that after fertilization of mouse oocytes, this domain disappeared and microfilaments were concentrated around pronuclei. Kim et al. (1996c) demonstrated that, in mature pig oocytes, two domains (a thick and a thin microfilament domain) are found in the oocyte cortex. Chromosomes are located in the thick microfilament domain of the cortex, which may be important for polar body extrusion and normal development during fertilization. In the present study, microfilaments in the pig oocyte concentrated in both the male and female chromatin after sperm penetration. Although the mechanism controlling microfilament polymerization during fertilization is elusive at present, microfilaments above both nuclear structures may arise from a polymerization of actin recruited from the egg cytoplasm. Van Blerkom and Bell (1986) have shown that, in mice, chromosomes gain the capacity to modify the organization of microfilaments in their vicinity during oocyte maturation. After sperm penetration, a rapid series of increases of intracellular calcium ions has been observed in many species (Mivazaki et al., 1993: Machaty et al., 1997). Battaglia and Gaddum-Rosse (1987) showed that an increase in calcium ions in the rat egg cytosol was directly or indirectly associated with changes in the actin cytoskeleton. Therefore, after sperm penetration or parthenogenetic activation an increase in calcium ions may affect cortical microfilament assembly. In this study, treatment with cytochalasin B did not completely inhibit movement of both pronuclei after pronuclear formation, but did prevent union of the nuclei at the oocyte centre. Webb et al. (1986) demonstrated that a microfilament-rich domain initially overlying the meiotic spindle disappeared during ageing of the mouse oocyte. In such conditions, the spindle with chromatin migrated toward the centre of the egg. In aged pig oocytes, the metaphase chromatin is also frequently located outside of the microfilament rich domain (Kim et al., 1996a). Migration of chromatin from the dense microfilament domain may be the major cause of formation of two female pronuclei without polar body extrusion in aged eggs since polar body extrusion is dependent upon the organization of the microfilaments (Maro et al., 1986). In sheep oocytes, after extended exposure to cytochalasin D, the metaphase spindle of the second meiotic division migrated toward a subcortical region and became tangentially, instead of radially, oriented (Le Guen et al., 1989). Therefore, previous results and the present study suggest that microfilaments are involved in maintaining the spindle in a cortical position. Disruption of microfilament assembly may result in the release of chromatin from the cortex of the oocyte.

Advances in in vitro maturation and in vitro fertilization have increased the availability of pig embryos for the study of early zygotic development. However, abnormal spindle formation, asynchronous pronuclear formation and an abnormally high incidence of polyspermy have repeatedly been observed in pig oocytes after in vitro maturation and in vitro fertilization (Funahashi et al., 1994; 1996, Kim et al., 1996a,b). Normal and abnormal patterns of nuclear structures and cytoskeletons during maturation, in vitro fertilization and parthenogenetic activation have been observed in pigs (Kim et al., 1996 a,b,c; Funahashi et al., 1996) suggesting that inadequate culture 
conditions during in vitro maturation and in vitro fertilization impair the function of cytoplasmic organelles, including microtubule and microfilament assembly, and results in abnormal pronuclear formation after fertilization and a lower incidence of early embryonic development. In the present study, the roles of microtubules and microfilaments and their interactions during fertilization and parthenogenesis in pig oocytes were examined. The results help to provide insight into strategies for improving in vitro maturation and in vitro fertilization conditions in pigs.

In conclusion, the results of the present study suggest that both microtubules and microfilaments are integrated during fertilization and may not be required for pronuclear formation, but are required for the union of sperm and egg nuclei leading to subsequent cell division.

The authors thank T. Phillips and M. Stanley in the Molecular Cytology Core Facility at University of Missouri-Columbia for the use of confocal microscopy and preparing photomicrographs. They also thank H. Funahashi for his critical advice, and B. Nichols for secretarial assistance in preparation of the manuscript. This work was funded by USDA grant 94-37203-1087. Contribution from the Missouri Agricultural Experiment Station. Journal Series Number 12,502 .

\section{References}

Albertson DG (1984) Formation of the first cleavage spindle in nematode embryos Developmental Biology 101 61-72

Battaglia DE and Gaddum-Rosse P (1987) Influence of the calcium ionophore A23187 on rat egg behavior and cortical F-actin Gamete Research 18 $141-152$

Breed WG, Simerly C, Navara CS, VandeBerg JL and Schatten G (1994) Microtubule configurations in oocytes, zygotes, and early embryos of a marsupial Monodelphis domestica. Developmental Biology 164 230-240

Funahashi H and Day BN (1993) Effects of the duration of exposure to supplemental hormones on cytoplasmic maturation of pig oocytes in vitro. Journal of Reproduction and Fertility 98 179-185

Funahashi H, Cantley TC, Stumpf TT, Terlouw SL and Day BN (1994) In vitro development of in vitro matured porcine oocytes following chemical activation or in vitro fertilization Biology of Reproduction 50 1072-1077

Funahashi H, Kim N-H, Stumpf TT, Cantley TC and Day BN (1996) Presence of organic osmolytes in maturation medium enhances cytoplasmic maturation of porcine oocytes Biology of Reproduction 54 1412-1419

Kim N-H, Moon SJ, Prather RS and Day BN (1996a) Cytoskeletal alteration in aged oocytes and parthenogenesis Molecular Reproduction and Development 43 513-518

Kim N-H, Simerly C, Funahashi H, Schatten G and Day BN (1996b) Microtubule organization in porcine oocytes during fertilization and parthenogenesis Biology of Reproduction 54 1397-1404

Kim N-H, Funahashi H, Prather RS, Schatten G and Day BN (1996c) Microtubule and microfilament dynamics in porcine oocytes during meiotic maturation Molecular Reproduction and Development 43 248-255

Le Guen P and Crozet N (1989) Microtubule and centrosome distribution during sheep fertilization European Journal of Cell Biology 48 239-249
Le Guen PL, Crozet N, Huneau D and Gall L (1989) Distribution and role of microfilaments during early events of sheep fertilization Gamete Research 22 411-425

Long CR, Pinto-Correia C, Duby RT, Ponce de Leon FA, Boland MP, Roche JF and Robl JM (1993) Chromatin and microtubule morphology during the first cell cycle in bovine zygotes Molecular Reproduction and Development 36 23-32

Machaty Z, Funahashi H, Day BN and Prather RS (1997) Developmental changes in the intracellular $\mathrm{Ca}^{2+}$ release mechanisms in porcine oocytes Biology of Reproduction 56 921-930

Maro B, Johnson MH, Pickering SJ and Flach G (1984) Changes in the actin distribution during fertilization of the mouse egg Joumal of Embryology and Experimental Morphology 81 211-237

Maro B, Howlett SK and Webb M (1985) Non-spindle microtubule organizing centers in metaphase Il-arrested mouse oocytes Journal of Cell Biology 101 1665-1672

Maro B, Johnson MH, Webb M and Flach G (1986) Mechanism of polar body formation in the mouse oocyte: an interaction between the centrosomes, the cytoskeleton and plasma membrane Journal of Embryology and Experimental Morphology $9211-32$

Miyazaki S, Shirakawa H, Nakada K and Honda Y (1993) Essential role of the inositol 1,4,5-triphosphate receptor $/ \mathrm{Ca}^{2+}$ release channel in $\mathrm{Ca}^{2+}$ waves and $\mathrm{Ca}^{2+}$ oscillations at fertilization of mammalian eggs Developmental Biolugy $15862-78$

Petters RM and Wells KD (1993) Culture of pig embryos fournal of Reprodiction and Fertility Supplement 48 61-73

Rieder CL and Salmon ED (1994) Motil kinetochores and polar ejection forces dictate chromosome position on the vertebrate mitotic spindle Journal of $\mathrm{Cell}_{\mathrm{l}}$ Biology 124 223-233

Schatten G (1994) The centrosome and its mode of inheritance: the reduction of the centrosome during gametogenesis and its restoration during fertilization Developmental Biology 165 299-335

Schatten G, Simerly C and Schatten H (1985) Microtubule configurations during fertilization, mitosis and early development in the mouse and the requirement for egg microtubule-mediated motility during mammalian fertilization Proceedings of the National Academy of Science USA 82 4152-4156

Schatten G, Schatten H, Spector I, Cline C, Paweletz N, Simerly C and Petzelt C (1986) Latrunculin inhibits the microfilament-mediated processes during fertilization, cleavage and early development in sea urchins and mice Experimental Cell Research 166 191-208

Schatten H, Simerly C, Maul G and Schatten G (1989) Microtubule assembly is required for the formation of the pronuclei, nuclear lamin acquisition, and DNA synthesis during mouse, but not sea urchin, fertilization Gamete Reseurch 23 309-322

Simerly C and Schatten G (1993) Techniques for localization of specific molecules in oocytes and embryos Methods in Enzymology 225 516-552

Van Blerkom J and Bell H (1986) Regulation of development in the fully grown mouse oocyte: chromosome-mediated temporal and spatial differentiation of cytoplasm and plasma membrane Journal of Embryology and Experimental Morphology 93 213-238

Webb M, Howletts K and Maro B (1986) Parthenogenesis and cytoskeleton organization in aging mouse eggs journal of Embryology and Experimental Morphology 95 131-145

Yllera-Fernandez MDM, Crozet N and Ahmed-Ali M (1992) Microtubule distribution during fertilization in the rabbit Molecular Reproduction and Development 32 271-276

Zernicka-Goetz M, Kubiak JZ and Antony C, Maro B (1993) Cytoskeletal organization of rat oocytes during metaphase II arrest and following abortive activation: a study by confocal laser scanning microscopy Molecular Reproduction and Development 35 165-175 